\title{
DIAGNÓSTICO DA MORTALIDADE DE PEDESTRES NOS ESTADOS BRASILEIROS: EVOLUÇÃO DAS TAXAS DE MORTES
}

\author{
G. P. Caldeira ${ }^{1}$; B. P. Branco ${ }^{1,2}$; J. T. Bastos ${ }^{1,3}$ \\ ${ }^{1}$ Universidade Federal do Paraná, Rua Evaristo F. F. da Costa, 418, Jd. das Américas, Curitiba/PR \\ ${ }^{2}$ Observatório Nacional de Segurança Viária, R. 9 de Julho, 1953, Vila Georgina, Indaiatuba \\ gabrielcaldeira@ufpr.br', beatriz.branco@onsv.org.br ${ }^{2}, j t b a s t o s @ u f p r . b r^{3}$
}

Resumo: Dado o cenário de mortalidade no trânsito com uma elevada participação dos pedestres do total de mortes no trânsito no Brasil, esta pesquisa tem por objetivo analisar esta situação e construir um diagnóstico da mortalidade de pedestres nos estados brasileiros, com destaque para os contrastes regionais em relação à evolução das taxas de mortes. Destacam-se as reduções substanciais em praticamente todos os estados da taxa de mortes de pedestres por 10 mil veículos, o que está em grande parte associado ao elevado aumento da frota de veículos no período 2000-2015.

Palavras-chave: Pedestres, Mortalidade, Estados brasileiros.

\section{Introduçáo}

No meio urbano brasileiro as condiçôes de circulação dos pedestres são, em geral, precárias e não há uma rede de transporte a pé com níveis adequados de segurança e conveniência [1], apesar das viagens a pé representarem 36,5\% das viagens realizadas nas cidades em 2014 [2].

\section{Metodologia}

A metodologia incluiu a coleta de dados secundários estaduais no período 2000-2015 referentes a vítimas fatais em atropelamentos (DATASUS) [3], frota de veículos (DENATRAN) [4] e a população (IBGE) [5] e posterior análise comparativa dos dados.

\section{Resultados esperados/Conclusóes}

Para a análise da série histórica nos estados em relação ao número de óbitos de pedestres e à taxa de óbitos de pedestres por 100 mil habitantes, destacam-se os estados com elevadas reduçóes no período 2000-2015 (BA, DF, ES e RJ) e os estados com grandes aumentos (MA, PA, PI e RO). Em relação à série histórica da taxa de óbitos de pedestres por 10 mil veículos, observou-se reduçôes substanciais em praticamente todos os estados, o que está em grande parte associado ao elevado aumento da frota de veículos no período 2000-2015. Na comparação entre os anos de 2000 e 2015, todos os estados apresentaram redução na participação dos pedestres no total de óbitos. Merecem destaque as reduçôes verificadas nos seguintes estados: AP, MA, MS, PI e RJ. 


\section{Referências}

[1] GOLD, Philip (Brasil). Qualidade de Calçadas no Município de Sáo Paulo. São Paulo: Gold Projects, 2004.

[2] ASSOCIAÇÃO NACIONAL DE TRANSPORTES PÚBLICOS (ANTP) (Brasil) (Org.). Relatório Geral 2014. São Paulo, 2016. 96 p.

[3] BRASIL. Ministério da Saúde. Sistemas de Informaçôes de Mortalidade - DATASUS. Mortes por causas externas no período 2000-2015. Disponível em: <http://www2.datasus.gov.br/DATASUS>. Acesso em: 10 ago. 2017.

[4] BRASIL. Ministério das Cidades. Departamento Nacional de Trânsito - DENATRAN. Frota de veículos no período 2000-2015. Disponível em: <http://www.denatran.gov.br/frota.htm>. Acesso em: 10 ago. 2017.

[5] BRASIL. Ministério do Planejamento Orçamento e Gestão. Instituto Brasileiro de Geografia e Estatística IBGE. População no Brasil de 2000-2015. Disponível em: <https://ww2.ibge.gov.br/home/estatistica/populacao>. Acesso em: 10 ago. 2017. 